\title{
RETRACTED ARTICLE: Existence of solutions of nonlocal initial value problems for differential equations with Hilfer-Katugampola fractional derivative
}

\author{
S. Harikrishnan ${ }^{1}$ - K. Kanagarajan ${ }^{1}$ - E. M. Elsayed ${ }^{2}$ (D) \\ Received: 16 March 2018 / Accepted: 1 February 2019 / Published online: 18 February 2019 \\ (c) The Royal Academy of Sciences, Madrid 2019
}

This article [1] is retracted by Editor because the article shows significant overlap with a previously published article by Bhairat et al [2]. E. M. Elsayed agrees to this retraction, S. Harikrishnan and K. Kanagarajan have not responded to any correspondence from the editor/publisher about this retraction. [1] Harikrishnan, S., et al. "Existence of Solutions of Nonlocal Initial Value Problems for Differential Equations with Hilfer-Katugampola Fractional Derivative.” Revista De La Real Academia De Ciencias Exactas, Físicas y Naturales. Serie A. Matemáticas, 2019, https://doi.org/10.1007/s13398-019-00645-0. [2] Bhairat, Sandeep P., and Dnyanoba-Bhaurao Dhaigude. "Existence of Solutions of Generalized Fractional Differential Equation with Nonlocal Initial Condition." Mathematica Bohemica, 2018, pp. 1-18., https://doi.org/10.21136/mb.2018.0135-17".

Publisher's Note Springer Nature remains neutral with regard to jurisdictional claims in published maps and institutional affiliations.

Electronic supplementary material The online version of this article (https://doi.org/10.1007/s13398-01900645-0) contains supplementary material, which is available to authorized users.

$凶$ S. Harikrishnan

hkkhari1@gmail.com

1 Department of Mathematics, Sri Ramakrishna Mission Vidyalaya College of Arts and Science, Coimbatore 641020, India

2 Department of Mathematics, Faculty of Science, Mansoura University, Mansoura 35516, Egypt 